\title{
Gestão da Qualidade: tecendo olhares para a percepção dos clientes para o comércio de calçados da Cidade de Sousa, Paraíba
}

Quality Management: weaving glances for customer perception for the shoe trade in the City of Sousa, Paraíba

Gestión de la calidad: tejiendo conocimientos sobre la percepción de los clientes sobre el comercio del calzado en la Ciudad de Sousa, Paraíba

Recebido: 23/06/2021 | Revisado: 29/06/2021 | Aceito: 01/07/2021 | Publicado: 04/07/2021

Wyara Ferreira Melo

ORCID: https://orcid.org/0000-0001-7054-4060 Universidade Federal de Campina Grande, Brasil E-mail: wyara_mello@hotmail.com

José Cândido da Silva Nóbrega ORCID: https://orcid.org/0000-0002-0976-3763 Universidade Federal de Campina Grande, Brasil E-mail: jcandidosn@uol.com.br

Fagno Dallino Rolim

ORCID: https://orcid.org/0000-0001-6108-3071 Universidade Federal de Campina Grande, Brasil E-mail: dallino@hotmail.com Thiago Casimiro ORCID: https://orcid.org/0000-0002-6889-3509 Faculdade Santa Maria, Brasil E-mail: thiagocasimiro@ hotmail.com

Richard José Cavalcante Santos ORCID: https://orcid.org/0000-0002-6138-1391 Faculdade São Francisco, Brasil E-mail: zodiacozeus@hotmail.com

Adryele Gomes Maia

ORCID: https://orcid.org/0000-0002-7433-7138 Universidade Federal do Rio Grande do Norte, Brasil E-mail: adryelegm@gmail.com

\begin{abstract}
Resumo
A prestação de serviço tornou-se uma ferramenta essencial para os empreendimentos que buscam destaque em um mercado tão competitivo. Este trabalho apresenta dados de uma pesquisa realizada, quanto à percepção dos clientes para o comércio de calçados da cidade de Sousa - PB, como também, a partir da análise dos resultados traz teorias sobre qualidade no atendimento enriquecendo ainda mais o conteúdo do mesmo. Esta pesquisa é de caráter descritivo e a abordagem utilizada é à quantitativa. A Coleta de dados foi desenvolvida em lojas de calçados da cidade de Sousa - PB, a amostra estudada são clientes que frequentam tais empreendimentos, através do instrumento de pesquisa o questionário, tendo como objetivo identificar o que os consumidores da cidade de Sousa percebem do atendimento prestado pelas empresas do ramo varejista de calçados. A pesquisa foi realizada com 100 pessoas, $58 \%$ de homens e $42 \%$ de mulheres, nos resultados é notado uma mesma quantidade de pessoas representadas pelo percentual de $36 \%$ definem o atendimento prestado pelas lojas calçadistas que está bom e 36\% está regular, totalizando $72 \%$ dos respondentes. Conclui-se que através da análise dos resultados obtidos, pode-se inferir que os clientes das lojas de calçados da cidade de Sousa-PB, percebem uma boa qualidade no atendimento prestado.
\end{abstract}

Palavras-chave: Clientes; Empresa; Qualidade; Atendimento.

\begin{abstract}
Providing service has become an essential tool for enterprises seeking to highlight in such a competitive market. This paper presents data from a survey regarding the perception of customers for the footwear trade in the city of Sousa $\mathrm{PB}$, as well as from the analysis of the results brings theories about quality of care further enriching the contents. This research is descriptive and the approach is quantitative. The data collection was developed in shoe stores in the city of Sousa - PB, the studied sample are customers who attend such ventures through research tool the questionnaire. It aims to identify what consumers of the city of Sousa realize the care provided by companies in the retail industry shoes. The survey was conducted with 100 people, $58 \%$ of men and $42 \%$ women, the results are noticed the same number of people represented by the percentage of $36 \%$ define the service provided by footwear shops that are good
\end{abstract}


and $36 \%$ are regular, totaling $72 \%$ of respondents. In conclusion, by analyzing the results, we can infer that customers of shoe stores in the city of Sousa-PB, realize a good quality in the care provided.

Keywords: Customer; Company; Quality; Service.

\section{Resumen}

La prestación de servicios se ha convertido en una herramienta fundamental para las empresas que buscan destacarse en un mercado tan competitivo. Este trabajo presenta datos de una encuesta realizada, sobre la percepción de los clientes sobre el comercio de calzado en la ciudad de Sousa - PB, así como, a partir del análisis de los resultados, aporta teorías sobre la calidad de la atención, enriqueciendo aún más su contenido. Esta investigación es descriptiva y el enfoque utilizado es cuantitativo. La recolección de datos se desarrolló en zapaterías de la ciudad de Sousa - PB, la muestra estudiada son los clientes que asisten a dichas empresas, a través del instrumento de encuesta, el cuestionario, con el objetivo de identificar qué perciben los consumidores de la ciudad de Sousa sobre el servicio brindado por las empresas. en el sector minorista de calzado. La encuesta se realizó con 100 personas, 58\% hombres y $42 \%$ mujeres. Los resultados arrojan igual número de personas representado por el porcentaje del $36 \%$ que define el servicio que brindan las zapaterías que es bueno y el $36 \%$ es regular, totalizando $72 \%$ de encuestados. Se concluye que del análisis de los resultados obtenidos se puede inferir que los clientes de las zapaterías de la ciudad de Sousa-PB perciben una buena calidad en el servicio brindado.

Palabras clave: Clientes; Empresa; Calidad; Servicio.

\section{Introdução}

No comércio atual a maioria das empresas comercializam produtos semelhantes tanto em preço quanto em qualidade. Por esse motivo a prestação de serviço tornou-se uma ferramenta essencial para os empreendimentos que buscam destaque em um mercado tão competitivo (Okano,2020).

Desde o principio dos tempos, o homem busca de todas as formas aumentar a qualidade em tudo que criou. Nos segmentos organizacionais quando tratamos da qualidade atual, sabe-se que não é apenas mais uma ferramenta, mas sim um fator de sobrevivência, principalmente quando se trata de grandes empresas, as quais querem manter-se como destaque neste mundo tão concorrente (Rocha, 2020). Porém conquista-la, além de um grande desafio é também uma tarefa árdua e difícil.

A implantação dessa estratégia impõe o desafio de desenvolver uma vantagem competitiva, a qual o cliente perceba como um diferencial de um produto ou serviço, ou seja, alguma coisa que faça o cliente entender a diferença entre o produto de uma empresa à dos concorrentes (Santos et al., 2020).

À medida que um gestor opta pela qualidade total, deve estar focado em técnicas e táticas dedicadas a atrair novos e conservar os antigos clientes. Maximizar a fidelização exige identificar, quais são as causas principais de insatisfação dos consumidores, e logo após, procurar formas de corrigi-los em todas as áreas da organização (CHACHA, 2019).

Procurar uma forma de surpreender o consumidor é o principal objetivo das empresas, essa é a razão pela qual, muitas empresas apostam e investem muito em meios que auxiliem na conquista do consumidor final. Segundo Lovelock e Wright (2001) O serviço ao cliente significa todos os seus aspectos, atitudes e elementos que ampliem a capacidade do cliente de compreender o valor potencial de um produto ou serviço essencial.

Para Chiavenato (2000), no mundo globalizado que estamos vivendo é fundamental para as empresas a qualidade no atendimento ao cliente. Apesar disso, a excelência da qualidade no atendimento ao cliente, proporciona um grau de dificuldade muito elevado para alcançar. Isto ocorre porque atender bem o cliente depende de grandes mudanças em atitudes profissionais de todos os que compõem uma empresa. Isto se trata de mudar radicalmente a cultura e os comportamentos da empresa.

É uma lastima dizer que em um mercado tão inovador, ainda existem empresas que resistem em investir em mão-deobra qualificada, para eles isto é perca de tempo e de dinheiro. Por causa de tais pensamentos existem muitas organizações falidas ou com grandes problemas financeiros, pois não conseguem se sobressair por falta de clientes.

Diante dos conceitos e características apresentados, percebe-se a importância de realizar um estudo minucioso, com a finalidade de proporcionar aos leitores um maior conhecimento sobre o tema exposto: Gestão da Qualidade: tecendo olhares para a percepção dos clientes para o comércio de calçados da cidade de Sousa - PB, uma vez que o consumidor é atualmente o 
principal atrativo dos empreendimentos e um bom atendimento de qualidade é sem dúvidas uma excelente ferramenta para sair à frente dos concorrentes em um mercado tão competitivo. Desta forma busca-se neste trabalho, solucionar a seguinte questão: Qual a visão dos consumidores quanto à qualidade no atendimento prestado pelas lojas de calçados de Sousa-PB?

Diante do exposto é possível formular a hipótese de que os clientes percebem que as lojas de calçados da cidade de Sousa-PB proporcionam um bom atendimento, mas que podem melhorar cada ver mais, levando em consideração que o bom atendimento é um dos facilitadores para a fidelização do cliente em determinada loja.

Por essa razão as empresas buscam cada vez mais, aperfeiçoar as formas de atendimento, pois, o atendimento é constituído por um vinculo entre os atendentes e empreendimento, buscando alcançar o objetivo principal do mercado atual que é satisfazer as necessidades e desejos dos clientes. Dessa maneira, esse trabalho também proporcionará para os empresários, Identificar o que os consumidores da cidade de Sousa percebem do atendimento prestado pelas empresas do ramo varejista de calçados e assim corrigir algumas falhas cometidas, tornando possível obter as soluções dos pontos negativos, garantindo assim a melhoria da qualidade no atendimento ao cliente, elevando a imagem das empresas, diante da concorrência, fato imprescindível para a sobrevivência da mesma diante do mercado consumidor.

Esta pesquisa é de caráter descritivo, pois tem como objetivo primordial a descrição das características da população de clientes quanto à qualidade no atendimento e estabelecimento de relações entre variáveis (Gil, 2008).

A abordagem utilizada será a quantitativa. Este método é caracterizado pelo emprego da quantificação, tanto nas modalidades de coleta de informações, quanto no tratamento dessas através de técnicas estatísticas, desde as mais simples até as mais complexas (Dalfovo, Lana, \& Silveira, 2008).

O presente estudo foi realizado com 100 (cem) consumidores das lojas de calçados da cidade de Sousa PB, um pequeno local com segundo o IBGE (2010) 65.803 habitantes, onde 28.752 são "pessoas de 10 anos ou mais de idade com condição de atividade na semana de referência economicamente ativas" e o PIB (Produto Interno Bruto) é igual a 629.711 mil reais.

A amostra estudada foi de 100 clientes do comércio de calçados da cidade de Sousa-PB. Foram abordadas pessoas que se encontravam no centro de Sousa, onde se localiza a maior quantidade de comercio de calçados no período de 13 a 17 de abril de 2015. Amostra consiste em uma porção de pessoas que representem uma população (Cohen, Swerdlik, \& Sturman, 2014; Scalabrin \& Frizon, 2020).

O Instrumento de coleta de dados foi um questionário com 11 perguntas que tem como objetivo, determinar a percepção dos clientes em relação ao atendimento a eles prestados, visando identificar como são atendidos, conhecer como eles gostariam de ser atendidos, saber qual a sensação que o bom atendimento provoca ao consumidor, identificar os motivos que leva o mesmo a ser cliente de determinada loja (Sgarbossa \& Muraro, 2020).

O questionário "é o instrumento mais utilizado na pesquisa quantitativa, principalmente em pesquisas de grande escala, como as que se propõem levantas a opinião politica da população ou a preferência do consumidor" (Roesch, 2007, p. 142).

$\mathrm{Na}$ análise dos dados foi feita o agrupamento das informações coletados pelo o questionário que foi o estudo de uma amostra de 100 clientes do ramo de calçados, e serão organizados, apresentados e sintetizados através da utilização de gráficos e quadros que foi feita na planilha do Microsoft Excel 2013.

\section{Resultados e Discussão}

Conforme os dados apresentados no Quadro 1, o número de mulheres é superior a quantidade de homens, onde a diferença gerada entre os consumidores é de apenas $16 \%$. Representando, portanto, $58 \%$ de mulheres e $42 \%$ de homens, em 
uma amostra de 100 respondentes dos testes, isto porque segundo o IBGE (2010) o número de mulheres (34.008) ultrapassa a quantidade de homens (31.799) pertencentes a Sousa-PB.

Quadro 1: Gênero dos respondentes.

\begin{tabular}{|l|l|l|}
\hline Gênero & Quant. & $\%$ \\
\hline Feminino & 58 & $58 \%$ \\
\hline Masculino & 42 & $42 \%$ \\
\hline Total Geral & $\mathbf{1 0 0}$ & $\mathbf{1 0 0 \%}$ \\
\hline
\end{tabular}

Fonte: Dados da pesquisa (2015).

Segundo Rodrigues Júnior (2010), “As mulheres compram o dobro de calçados que os homens, tendo em média 20 pares de calçados femininos em seus armários”, confirmando os dados explicitados pelo Quadro 1.

Quadro 2: Faixa etária.

\begin{tabular}{|l|l|l|}
\hline Idade & Quant. & \% \\
\hline Entre 15 e 20 anos & 29 & $29 \%$ \\
\hline Entre 21 e 30 anos & 36 & $36 \%$ \\
\hline Mais de 30 anos & 35 & $35 \%$ \\
\hline Total Geral & $\mathbf{1 0 0}$ & $\mathbf{1 0 0 \%}$ \\
\hline
\end{tabular}

Fonte: Dados da pesquisa (2015).

No Quadro 2, onde trata da idade dos respondentes, é notável que 36\% dos consumidores entrevistados possuem entre 21 e 30 anos, $35 \%$ têm idade maior que 30 anos e somente $29 \%$ estão estre 15 e 20 anos de idade. Vale salientar que pelo menos $71 \%$ representa uma faixa etária de 21 anos acima, ou seja, estão situados na faixa de atividade produtiva, ganho de salário sendo assim maior gasto em produtos.

Figura 1: Classificação do Atendimento.

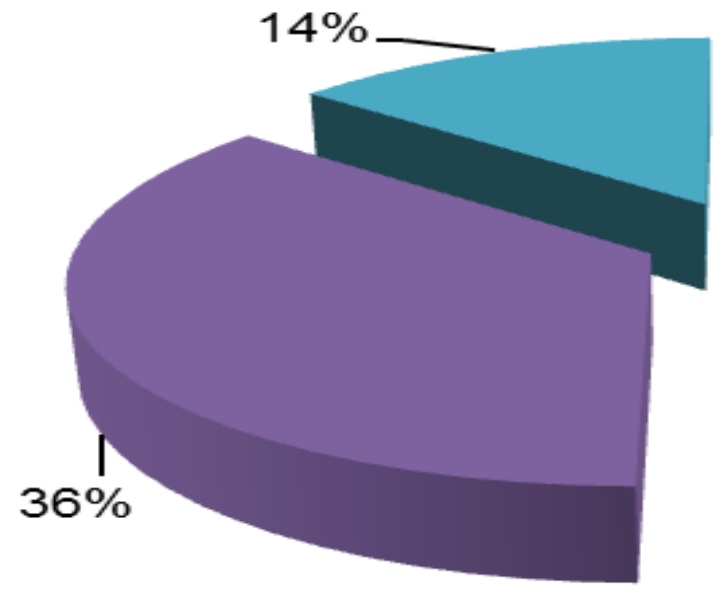

Bom

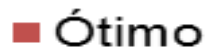

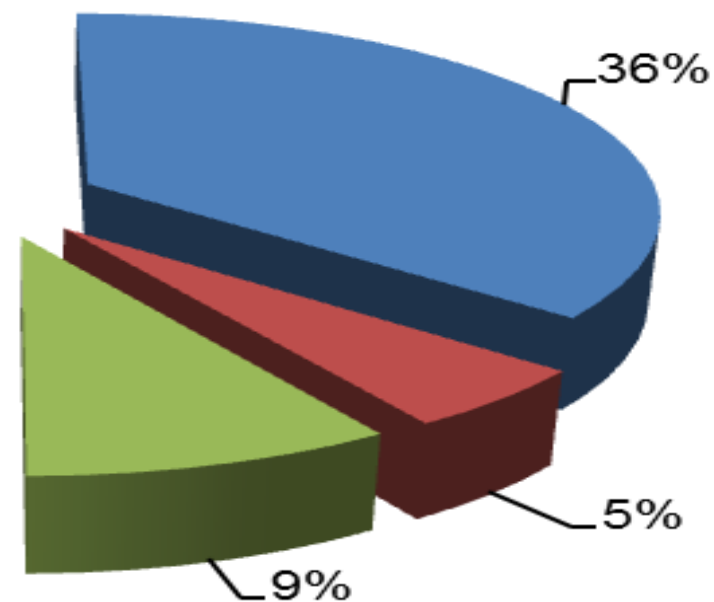

-9\% 
Na Figura 1 é notado uma mesma quantidade de pessoas representadas pelo percentual de $36 \%$ definem o atendimento prestado pelas lojas calçadistas estão entre bom e regular, totalizando $72 \%$ dos respondentes, seguidos por percentuais que indicam que 14\% dizem que atendimento é ruim, $9 \%$ afirmam ser péssimo e apenas 5\% qualificam como ótimo a qualidade no atendimento ao cliente, mostrando então que as empresas devem preocupar-se mais em atender bem, preocupando-se com seu bem dos seus clientes.

Figura 2: Definição do Bom Atendimento.

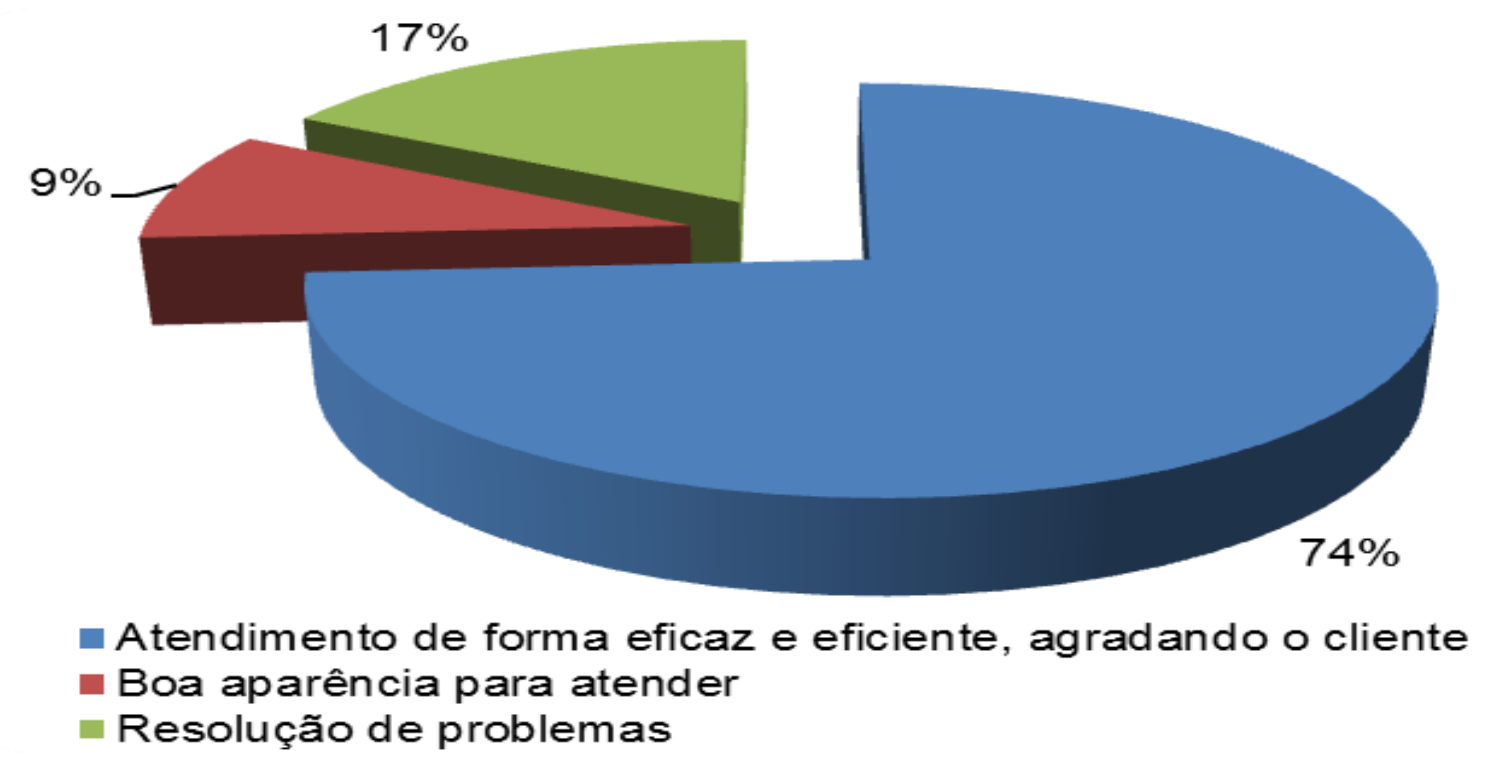

Fonte: Dados da pesquisa (2015).

Na Figura 2, o gráfico representa um total de 74\% definindo um bom atendimento como sendo uma forma de atender com eficiência e eficácia, de modo que agrade o cliente, $17 \%$ disseram que o bom atendimento é o que busca a resolução de problemas e 9\% dos respondentes disseram ser boa aparência para atender, sendo assim, fica claro que cada cliente tem sua maneira de entender o significado de atendimento de qualidade, cabe ao atendente saber diferenciar o tipo de cliente (Bertho, 2020).

Penna (1993) afirma que o atendimento diferenciado está vinculado a capacidade de cada funcionário ter uma percepção exata do cliente. É de necessidade extrema que o funcionário tenha auto percepção, ou seja, antes de atender o cliente, é de extrema importância que o funcionário esteja ciente do seu próprio comportamento (Castro, 2020).

Segundo Santos (1995), a sobrevivência de uma empresa depende mais que obter qualidade nos produtos, deve se dedicar inteiramente a garantir a qualidade dos serviços ao cliente fazendo com que se sintam: bajulados, ouvidos, respeitados, amados e encantados o tempo todo. 
Figura 3: Percepção dos clientes em relação a qualidade no atendimento nas lojas de calçados de Sousa-PB

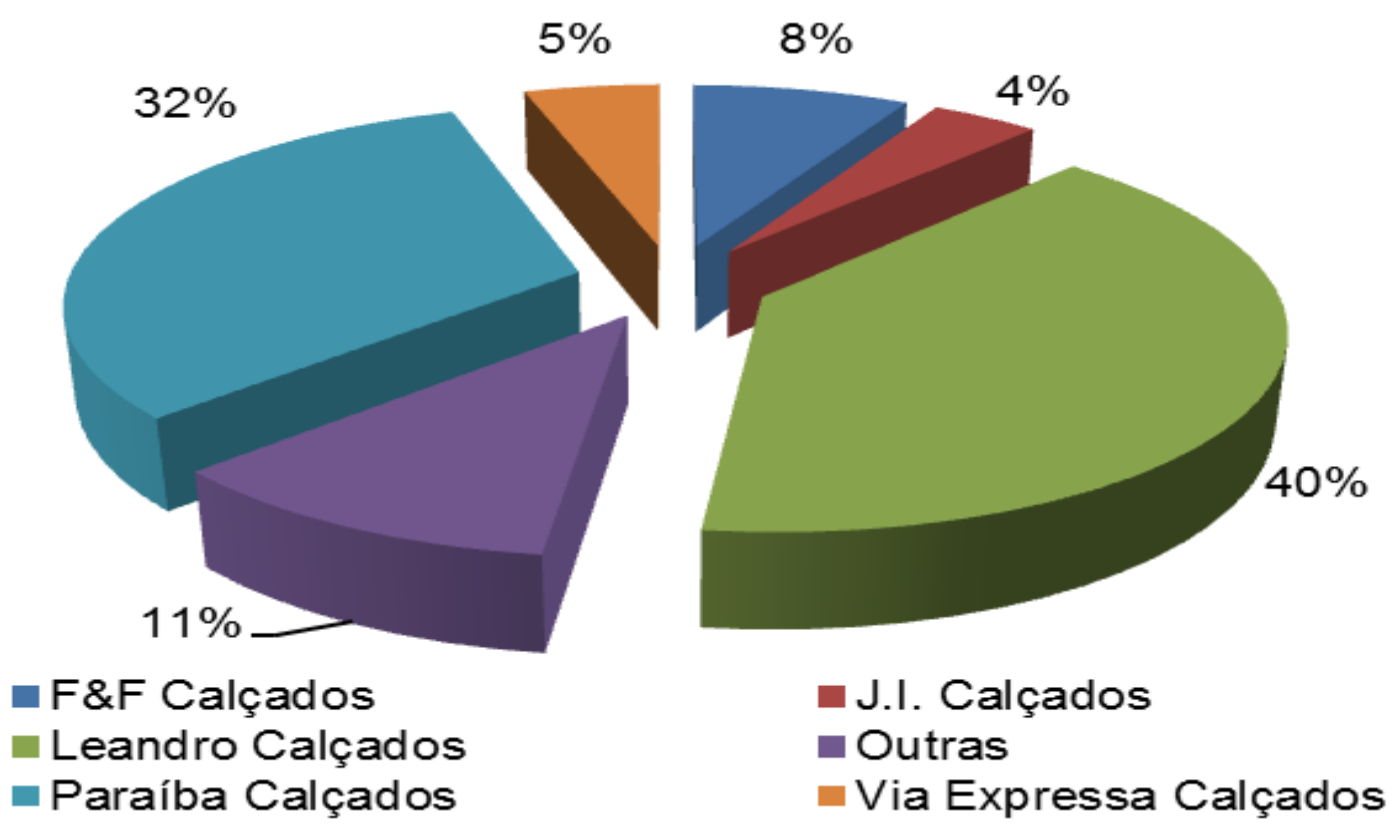

Fonte: Dados da pesquisa (2015).

A Figura 3, os respondentes qualificam a Loja Calçadista de Sousa que mais bem atende os clientes onde na classificação ficaram a loja Leandro Calçados com $40 \%$ dos votos, com $32 \%$ ficou a Paraíba Calçados, com 8\% ficou a J.I. Calçados, com 5\%.

Segundo Moraes et. al. (2013) Devido à legislação nacional e clientes mais exigentes, a competitividade esta mais presente nesta prestação de serviço. Por essa razão todas as empresas listadas acima oferecem um atendimento especial para cada tipo de cliente, na busca incessante de fidelizar eles (ALVES, 2019).

Silva e Zambon (2006) afirmam que, quando os clientes são bem atendidos e estão satisfeitos com o empreendimento voltam a comprar, demonstram lealdade e auxiliam no prosperar da empresa. Contudo, não há outra forma de atender bem que não seja por meio do conhecimento do comportamento de cada cliente.

Figura 4: Sentimento do cliente bem atendido.
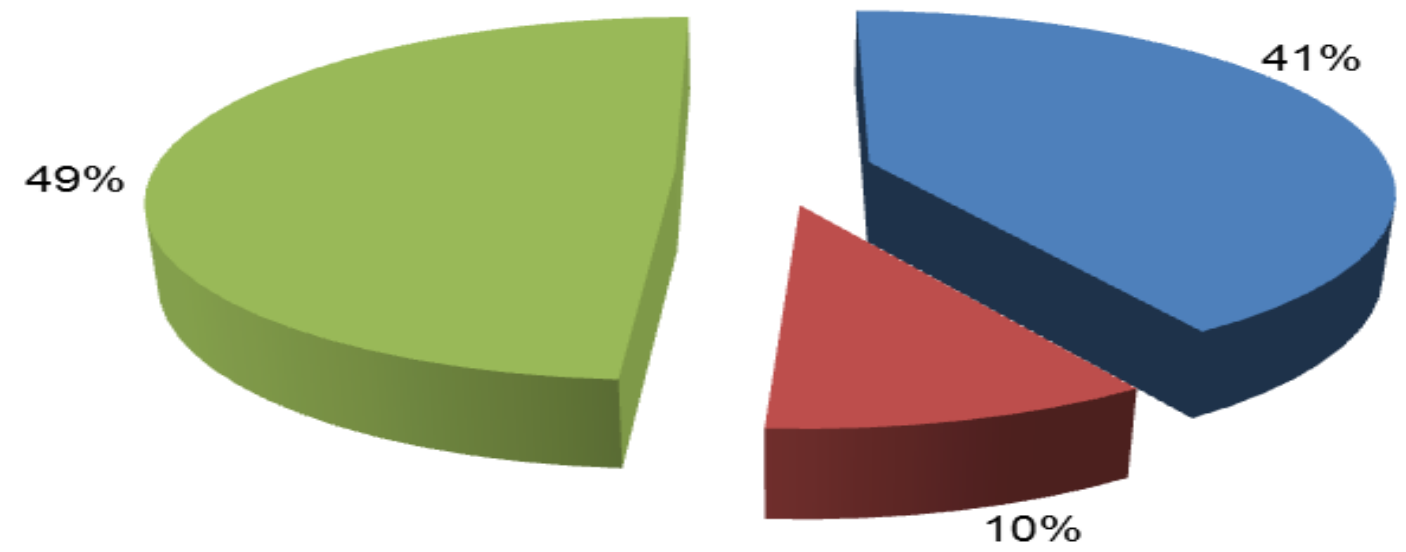

- Bem valorizado (a) $\quad$ Importante $=$ Satisfeito (a) e encantado (a) 
Na Figura 4, nota-se que a maioria dos respondentes, $49 \%$ afirmam que ao serem bem atendidos, sentem-se satisfeitos e encantados, $41 \%$ dizem se sentir bem valorizados e $10 \%$ sentem-se importantes.

Segundo Corrêa e Gianesi (1994, p. 79), "a avaliação que o cliente faz, durante ou após o término do processo, se dá através da comparação entre o que o cliente esperava do serviço, e o que percebeu do serviço prestado".

Para Maximiano (1997) afirma que a qualidade do atendimento significa o padrão mais elevado de desempenho, ou seja, o melhor que pode ser feito.

O cliente necessita sempre que os desejos e as necessidades deles sejam atendidos e todas as dúvidas sejam esclarecidas, por essa razão, o atendente deve mostrar-se cortês e atencioso, disponibilizando soluções para qualquer problema apontado pelo consumidor. Segundo Silva (2010), é importante ressaltar que quem define, avalia, o que é um atendimento de qualidade é o cliente pela maneira de como é atendido e se consegue satisfazer suas expectativas e necessidades.

Na Figura 5, observada abaixo, fica claro como é importante a ferramenta de qualidade no atendimento, pois $34 \%$, a maioria dos respondentes, disseram ser esta o principal motivo que os levam a efetuar uma compra, seguidos de $31 \%$ que dizem ser o preço o principal motivo, $30 \%$ estão voltados a qualidade dos produtos e por último com percentual de $5 \%$ afirmam ser a localização da empresa o motivo principal.

Figura 5: Motivo que leva o cliente a efetuar uma compra.

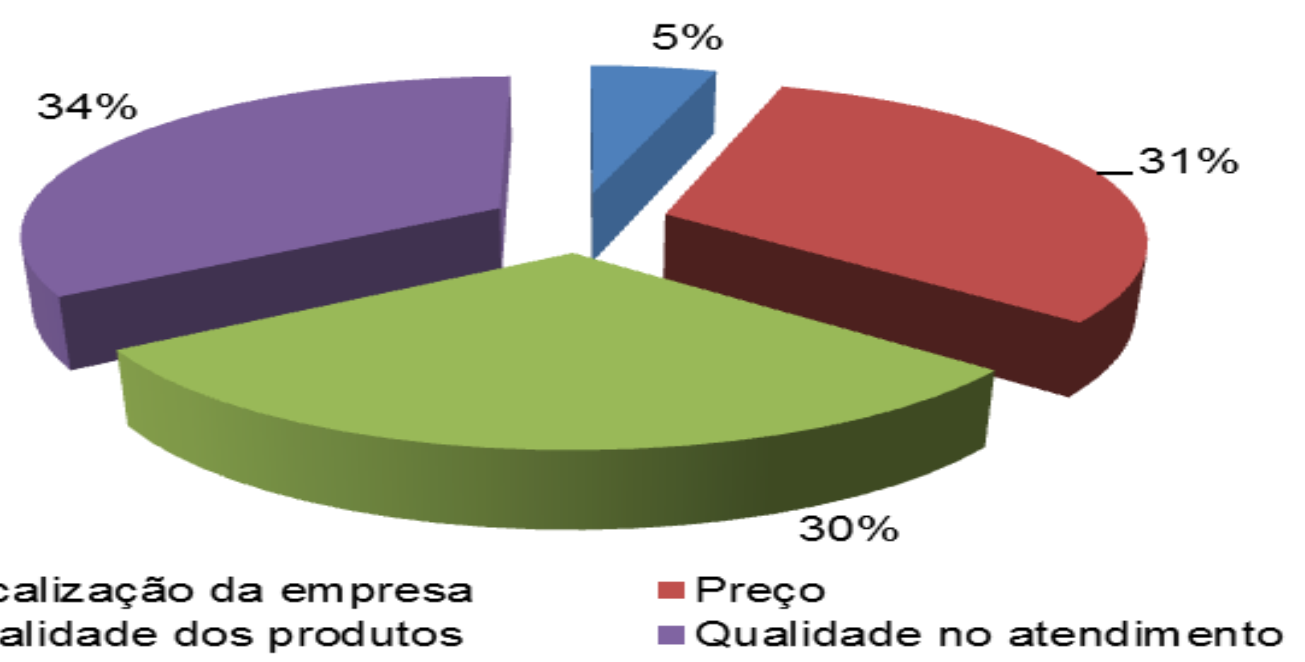

Fonte: Dados da pesquisa (2015).

Com a globalização e facilidades em adquirir produtos, vimos que a qualidade no atendimento marca o diferencial das empresas em ser competitivo e manter seus negócios atrativos aos olhos dos consumidores. O cliente torna-se exigente, colocando o preço não mais como o único fator de compra. As empresas dependem dos clientes, e investir em qualidade é sinônimo de investimento em longo prazo (Lopes, 2018).

Segundo Silva (2010), o atendimento com qualidade tem como objetivo principal conquistar novos clientes e manter os antigos, através do ato de atender com excelência. Silva ressalta ainda que o único avaliador do atendimento é o cliente, pela maneira do vendedor em satisfazer suas expectativas e necessidades.

Sendo assim, a pesquisa realizada confirma a explicação do autor, pois $75 \%$ dos respondentes afirmaram que "Sim", o atendimento prestado pelo vendedor influencia na decisão de comprar. Ainda no gráfico $14 \%$ dizem que não influenciam e $11 \%$ disseram talvez, mostrando incerteza ao responder a questão, como mostra a Figura 6. 
Figura 6: Influencia da Qualidade no atendimento na decisão de compra.

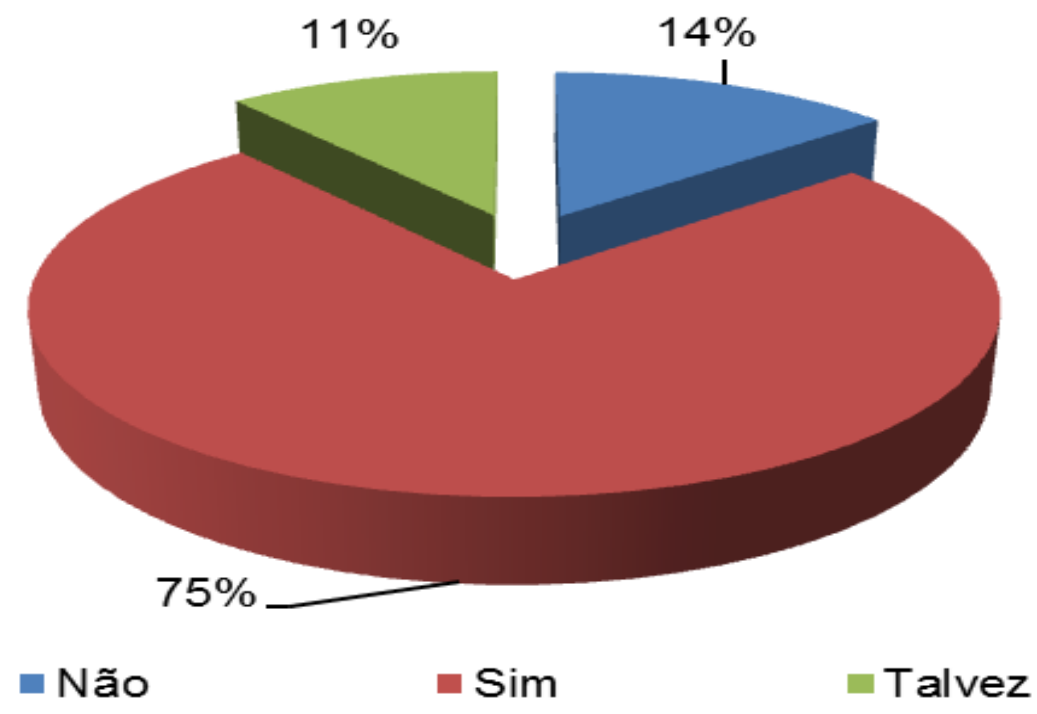

Fonte: Dados da pesquisa (2015).

Segundo Cobra (2009) o objetivo de todos que compõem uma empresa é de procurar "não apenas satisfazer as necessidades do cliente, mas também às suas mais exigentes expectativas”. Dessa forma, para que o processo de satisfação ocorra se faz necessário compreender o comportamento de cada cliente e o que ele realmente deseja ou espera da empresa.

Na Figura 7, a loja que compra-se com maior frequencia é a Paraíba Calçados representada no gráfico por $40 \%$ dos votos, seguida de Leandro Calçados 35\%, F\&F Calçados com 10\%, com percentual de 8\% estão Outras (lojas não citadas na questão), com $4 \%$ ficou J.I. Calçados e com 3\% Via Expressa Calçados.

Figura 7: Frequência de Compradores

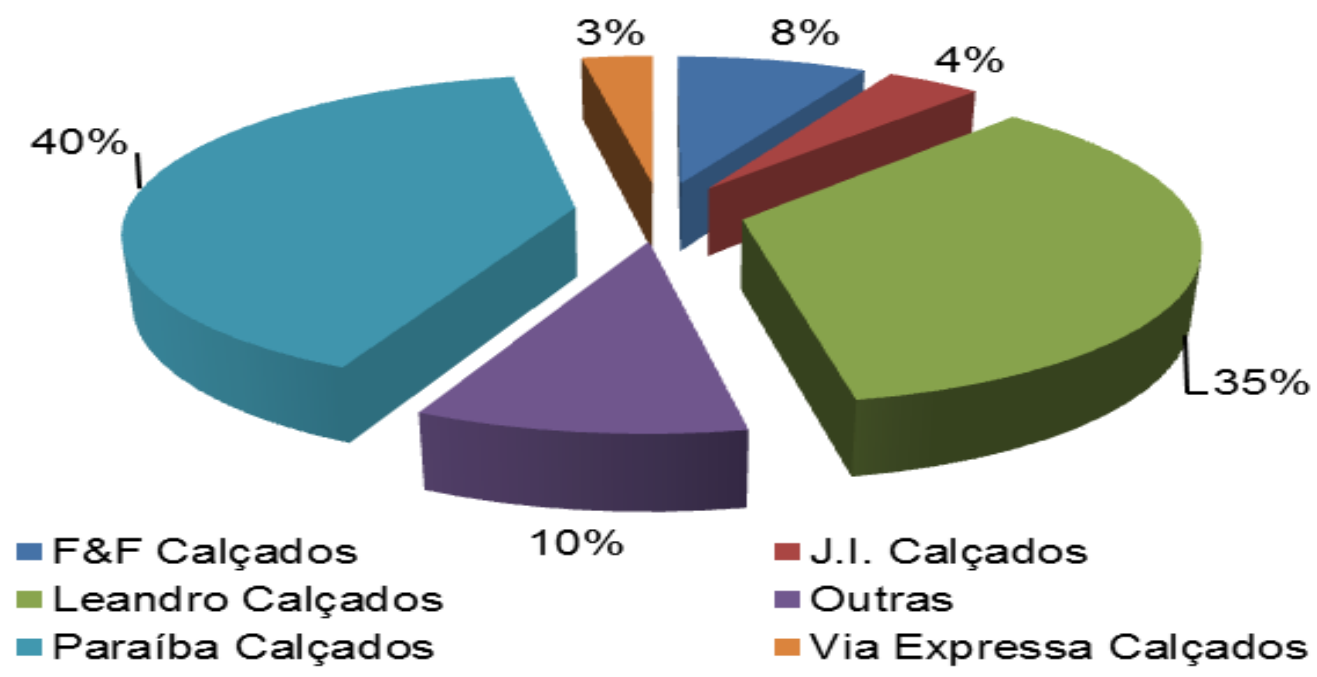

Fonte: Dados da pesquisa (2015).

Segundo Roesch (2007), o ponto principal, que leva os clientes a comprarem um produto ou serviço de um empreendimento é que todos os consumidores possuem problemas que precisam ser resolvidos e caso uma empresa esteja despreparada ou desatenta, poderá perder os clientes para outra organização que ajude-o a colher os benefícios. Ou seja, uma empresa bem preparada é aquela que consegue de alguma forma satisfazer as necessidades e os desejos do consumidor. 
Figura 8: Indicação de Lojas por Clientes.

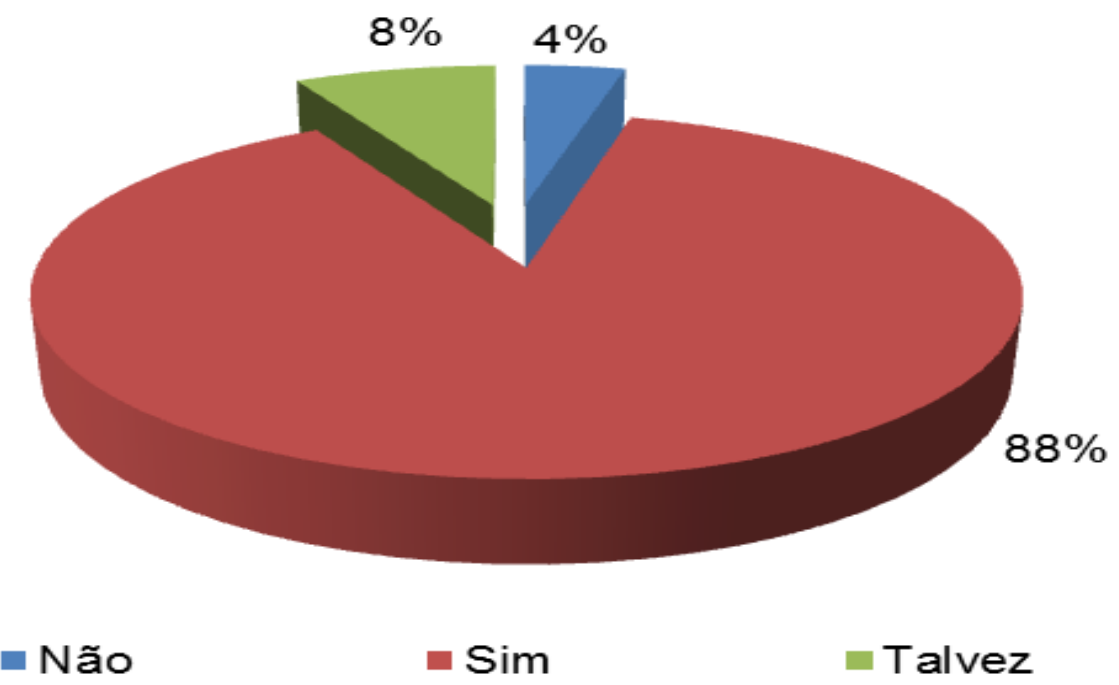

Fonte: Dados da pesquisa (2015).

Na Figura 8, 4\% dos entrevistados disseram não indicar a loja que mais frequentam, $8 \%$ afirmam que talvez indicassem e $88 \%$ afirmaram que indicariam a loja que mais frequentam. Com base no gráfico acima fica claro que quando um serviço gera satisfação, na maioria das vezes criam-se indicações de um cliente para outros, por essa razão, o mercado busca desenvolver meios para aperfeiçoar ainda mais os programas de qualidade existentes na empresa. "O compromisso com a qualidade vai determinar a solidez de uma empresa" (Townsend, 2010).

Figura 9: Indicação de Lojas por Clientes.

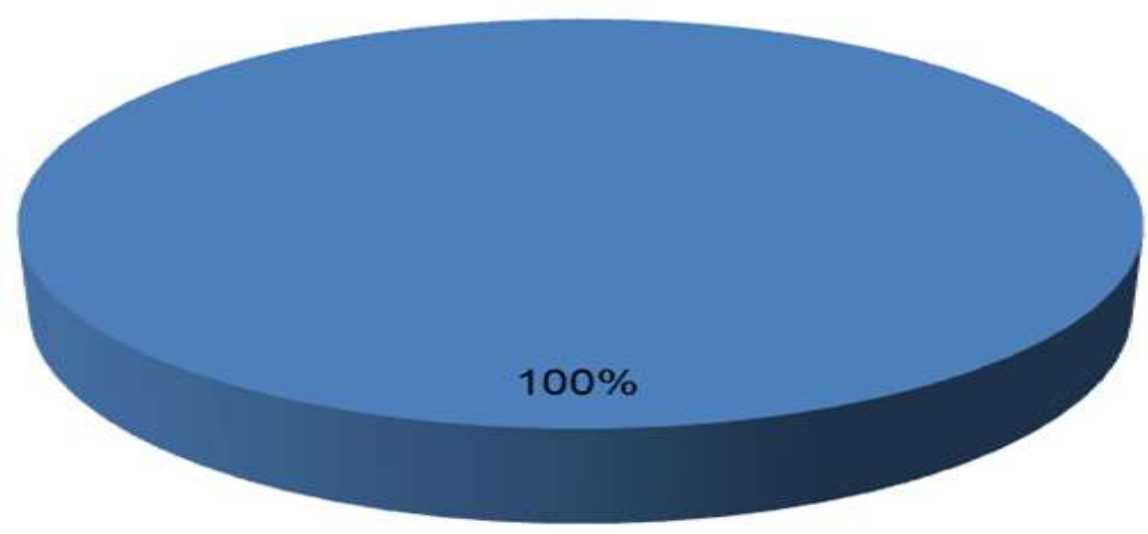

$=\operatorname{Sim}$

Fonte: Dados da pesquisa (2015).

A qualidade no atendimento é um grande diferencial que as empresas utilizam para estar à frente dos concorrentes, apresenta um alto grau de dificuldade, pois é necessário entender cada cliente, mas com a atualização mercadológica constante, existe um grande leque de benefícios, isto ocorre porque um atendimento de qualidade está diretamente ligado a atitude dos profissionais em todos os níveis (Endrici \& Grassano Neto, 2020).

Por esse motivo se faz necessário atender sempre bem os clientes pois, como visto nos dados expostos no gráfico, todo cliente precisa de um bom atendimento, sendo assim todos os profissionais que envolvem um empreendimento devem 
sempre atender bem. "Atender bem é se comprometer, relacionar com o resultado e o sucesso do cliente, se comportando como se fosse um consultor do cliente, aquele que tem prazer em levar solução para os problemas dos clientes." (Marques, 2013).

\section{Considerações Finais}

Nos dias atuais a preocupação com a satisfação e a qualidade no atendimento do cliente é um ponto forte, pois as organizações concebem o foco em seu publico.

A razão de ser uma empresa é a satisfação de seus clientes. Desta maneira toda sua administração deve estar voltada para qualidade no atendimento ao consumidor com peculiaridade, para satisfazê-lo, bem como um estudo empresarial baseado em parcerias organizacionais. O cliente sente-se satisfeito com o bom atendimento de acordo com a coleta de dados, 49\% dos entrevistados afirmam que ao serem bem atendidos, sentem-se satisfeitos e encantados, mostrando assim a sensação do cliente ao ser bem atendido, ficando claro como é importante a ferramenta de qualidade no atendimento, pois $34 \%$, a maioria dos respondentes, disseram ser esta o principal motivo que os levam a efetuar uma compra e $100 \%$ afirmam que é importante que haja uma boa qualidade no atendimento.

Atender o cliente com qualidade ou satisfazê-lo é uma filosofia empresarial baseada na parceria. É fundamental compreender que atender o cliente com qualidade, não se resume a trata-lo bem, com cortesia, mais do que isso significa acrescentar benefícios a serviços de qualidade, objetivando superar as expectativas dos clientes. $74 \%$ dos entrevistados definem um bom atendimento como sendo uma forma de atender com eficiência e eficácia, de modo que agrade o cliente. Então essa pesquisa mostra como os clientes gostariam de ser atendidos.

Conclui-se que através da análise dos resultados obtidos, pode-se inferir que os clientes das lojas de calçados da cidade de Sousa-PB, percebem entre bom e regular a qualidade no atendimento prestado, como consta nos dados obtidos 36\% dos entrevistados definem que o atendimento prestado pelas lojas calçadistas estão bom e $36 \%$ regular, totalizando $72 \%$ dos entrevistados.

Em suma este trabalho propõe um maior conhecimento sobre a percepção dos clientes quanto a qualidade do atendimento prestado pelas lojas de calçados da cidade de Sousa-PB, além de também proporcionar aos empresários a identificação de algumas falhas cometidas para corrigi-las, a fim de elevar o grau de afinidade com os consumidores e assim satisfazer suas necessidades e desejos.

\section{Referências}

Alves, A. M. L. (2019). Moda, economia criativa e economia circular: um plano de ação para o projeto Muçambê / Alzina Maria Leal Alves.

Bertho, M. A. C. (2020). A influência das relações de gênero na divisão de tarefas familiares e na violência entre parceiros íntimos. Dissertação. Universidade Federal de São Carlos. São Carlos.

Chacha, N. J. (2019). Atendimento Ao Cliente Como Factor Dinamizador Do Marketing De Relacionamento. Tese Universidade Católica de Moçambique. Nampula - Moçambique.

Castro, C. F. de. (2020). Análise do papel dos vendedores na satisfação de cliente por meio do NPS (Net Promoter Score): evidências do varejo de moda omnichannel brasileiro / Caio Faber de Castro.

Cobra, M. (2009). Administração de vendas. (4a ed.). Atlas.

Chiavenato, I. (2004). Introdução à Teoria Geral da Administração: uma visão abrangente da moderna administração das organizações. (7a ed.). Elsevier.

Chiavenato, I. (2000). Introdução à teoria geral da Administração. (6a ed.). Campus.

Cohen, R. J., Swerdlik, M. E., \& Sturman, E. D. (2014). Testagem e Avaliação Psicologica: Introdução a Testes e Medidas. AMGH Editora Ltda.

Corrêa, H. L., \& Gianesi, I. G. N. (1994). Administração estratégica de serviços: operações para a satisfação do cliente. Atlas.

Dalfovo, M. S., Lana, R. A., \& Silveira, A. (2008). Métodos Quantitativos e Qualitativos: Um Resgate Teórico. 
Research, Society and Development, v. 10, n. 8, e36510817491, 2021

(CC BY 4.0) | ISSN 2525-3409 | DOI: http://dx.doi.org/10.33448/rsd-v10i8.17491

Endrici, J. O. M., \& Grassano Neto, R. A. (2020). Qualidade Em Serviços: análise de indicadores do suporte técnico em empresa de tecnologia na cidade de Maringá-PR. Caderno de Administração, 28 (1).

Lovelock, C.; Wright, L. (2001). Serviços: Marketing e Gestão. Saraiva.

Lopes, S. D. C. (2018). Os meios de pagamento online: o seu impacto na concretização da compra por parte de consumidor português. Dissertação para obtenção do Grau de Mestre em Gestão Vila Nova de Famalicão

Rodrigues Júnior, F. (2010). Cotidiano. Clube dos Autores.

Gil, A. C. (2008). Métodos e Técnicas de Pesquisa Social. (6a ed.). Atlas.

Marques, W. L. (2013). Empregabilidade: Da Vida Profissional. Printed in Brazil.

Maximiano, A. C. A. (1997). Teoria geral da administração: escola científica na economia globalizada. Atlas.

Penna, A. G. (1993). Percepção e realidade: introdução ao estudo da atividade perceptiva. Imago.

Okano, M. T. (2020). A contribuição das Tecnologias da Informação e Comunicação (TICs) para a criação de valor nas empresas sociais. Tese. FVG.

Rocha, M. C. M. M. da R. (2020). Repensando Novas Estratégias e Cenários para a Construção do Conhecimento. Tese. Universidade Da Beira Interior.

Roesch, S. M. A. (2007). Projetos de estágio e de pesquisa em administração: guia para estágios, trabalhos de conclusão, dissertações e estudos de caso. (2a ed.). Atlas.

Santos, R. C. A., Dresch, A., \& Veit, D. R. (2020). Proposta de um Modelo Organizacional a uma Microempresa Prestadora de Serviços - Mom. Revista Gest@o.Org, V. 18, Edição 1.

Santos, J. J. (1995). Encantar o cliente dá lucro - Revolucione sua empresa e ame os seus clientes: fatores primordiais de diferenciação dos concorrentes. Ed. Campus.

Scalabrin, A. I., \& Frizon, J. A. (2020). Estratégias Mercadológicas Para Obtenção De Vantagem Competitiva No Setor Calçadista. R. Gest. Anál., 9(2).

Silva, F. G., \& Zambon, M. S. (2006). Gestão do relacionamento com o cliente. Thomson, 2006.

Silva, V. (2010). Marketing pessoal e vendas chefia e liderança telemarketing comunicação e expressão Verbal. Clube de Autores.

Sgarbossa, M., \& Muraro, M. (2020). Balanced scorecard: utilização da perspectiva do cliente na avaliação do supermercado x. Revista GESTO: Revista de Gestão Estratégica de Organizações. v. 8(2).

Townsend, P. L. (2010). Compromisso com a qualidade. Campus. 